\title{
Bacterial infections in cirrhosis: role of proton pump inhibitors and intestinal permeability
}

\author{
Lotte G. van Vlerken ${ }^{*}{ }^{1}$, Ellen J. Huisman ${ }^{*}, 1$, Bart van Hoek $^{\dagger}$, Willem Renooij $^{\ddagger}$, Felix W. M. de Rooij ${ }^{\S}$, \\ Peter D. Siersema* and Karel J. van Erpecum* \\ ${ }^{*}$ Department of Gastroenterology and Hepatology, University Medical Center Utrecht, Utrecht, ${ }^{\dagger}$ Department of \\ Gastroenterology and Hepatology, Leiden University Medical Center, Leiden, ${ }^{\ddagger}$ Department of Surgery, University Medical \\ Center Utrecht, Utrecht, ${ }^{\S}$ Department of Internal Medicine, Erasmus Medical Center, Rotterdam, The Netherlands
}

\begin{abstract}
Background Cirrhotic patients are at considerable risk for bacterial infections, possibly through increased intestinal permeability and bacterial overgrowth. Proton pump inhibitors (PPIs) may increase infection risk. We aimed to explore the potential association between PPI use and bacterial infection risk in cirrhotic patients and potential underlying mechanisms in complementary patient and animal models.
\end{abstract}

Materials and methods Bacterial overgrowth was determined in jejunum of 30 rats randomly allocated to 6-week PPI treatment, gastrectomy or no treatment. In 84 consecutive cirrhotic patients, bacterial infection risk was prospectively assessed and related to PPI use. Intestinal permeability was determined by polyethylene glycol (PEG) test in nine healthy individuals and 12 cirrhotic patients.

Results Bacterial overgrowth was much more common in jejunum of rats treated with PPI or gastrectomy compared with nontreated rats. Twenty-four patients $(29 \%)$ developed a bacterial infection during a median follow-up of 28 months. Although PPI users tended to experience infection more often than patients without $\mathrm{PPI}$ therapy, PPI use was not an independent predictor of bacterial infection (HR 1.2, 95\% $\mathrm{Cl} 0 \cdot 5-3 \cdot 0, P=0 \cdot 72)$, after correction for Child-Pugh class (HR 3.6, 95\% Cl 1.5-8.7, $P=0.004)$ and age (HR 1.05, 95\% Cl 1.01-1.09, $P=0.02)$. In cirrhotic patients, 24-h urinary recovery of PEGs 1500 and 3350 was significantly higher compared with healthy controls.

Conclusions Although in our animal model PPIs induced intestinal overgrowth, stage of liver disease rather than PPI use was the predominant factor determining infection risk in cirrhotic patients. Increased intestinal permeability may be a factor contributing to infection risk.

Keywords Acid-suppressive therapy, bacterial infection, bacterial overgrowth, intestinal permeability, proton pump inhibitors, spontaneous bacterial peritonitis.

Eur J Clin Invest 2012; 42 (7): 760-767

\section{Introduction}

Patients with liver cirrhosis are at increased risk for developing a broad range of bacterial infections, including spontaneous bacterial peritonitis (SBP), urinary tract infections, pneumonia, skin infections and bacteraemia/sepsis [1-3]. In approximately $30 \%$ of cirrhotic patients admitted to the hospital, a bacterial infection is diagnosed [2,3]. The development of bacterial infections leads to prolonged hospital stay and increased morbidity and mortality $[2,4,5]$. Although the exact mechanism by which bacterial infections develop in cirrhotic patients is unknown,

${ }^{1}$ These authors contributed equally to this work. increased intestinal permeability may promote bacterial translocation and increase infection rate [6-10]. In addition, cirrhotic patients often exhibit complement deficiency, reticuloendothelial system depression and leucocyte dysfunction $[1,11,12]$.

Acid-suppressive therapy with proton pump inhibitors (PPIs) or $\mathrm{H} 2$ receptor antagonists (H2RAs) could in theory also contribute to the development of bacterial infections, as their use is associated with bacterial overgrowth in the small intestine. H2RAs have been found to increase the risk of bacterial infections (especially pneumonia) in intubated intensive care patients [13]. Furthermore, a recent meta-analysis found an 
increased risk of community-acquired pneumonia in adult PPI users [14]. As far as cirrhotics are concerned, four retrospective studies on the association between PPI use and risk of SBP in cirrhotic inpatients with ascites reported contradictory results [6,15-18]. It remains unknown whether acid-suppressive therapy increases specifically the risk of SBP or risk of bacterial infections in general in cirrhotic patients.

In this study, we explored in a rat model, potential adverse effects of 6-week administration of high-dose PPIs on bacterial overgrowth and evaluated the potential association between use of acid-suppressive drugs and risk of various bacterial infections in cirrhotic outpatients. In addition, we assessed intestinal permeability in this patient group.

\section{Methods}

\section{Rat study}

Animals and conditions. Thirty-two male Wistar rats (Harlan CPB, Austerlitz, the Netherlands), weighing approximately $175 \mathrm{~g}$, were housed under standard laboratory conditions. Rats were randomly allocated to three experimental groups. Rats in group A $(n=10)$ received omeprazole (Astra Zeneca, Gothenburg, Sweden) in a dose of $400 \mu \mathrm{g} / \mathrm{kg}$ daily by oral gavage, which is equivalent to $80 \mathrm{mg}$ omeprazole administered to humans. Two milligram per millilitre of $\mathrm{NaHCO}_{3}$ (Sigma, Steinheim, Germany) was added to the omeprazole, and this was suspended in $0.3 \%$ hydroxypropyl methylcellulose (Sigma), adjusted to $\mathrm{pH} 9.0$ with $\mathrm{NaOH}$. Rats in group $\mathrm{B}(n=12)$ were subjected to gastrectomy with oesophagojejunostomy (GEJ) in order to investigate the effect of total achlorhydria. Twelve rats were operated based on our previous experience that approximately $20 \%$ of the rats will be lost because of postoperative complications. Rats in group C $(n=10)$ served as controls. All rats were sacrificed after 6 weeks. Throughout the experiment, animals had access to commercial semisynthetic rat chow (Hope Farms, Woerden, the Netherlands) and drinking water ad libitum.

Surgical techniques. Rats in group B were anaesthetized with a gaseous mixture of $3 \%$ isoflurane, $64 \% \mathrm{~N}_{2} \mathrm{O}$ and $33 \% \mathrm{O}_{2}$. Gastrectomy was performed through median laparotomy with the oesophagus attached end-to-site to the jejunum, $3 \mathrm{~cm}$ distal of the ligament of Treitz. Buprenorphin $(0.05 \mathrm{mg} / \mathrm{kg})$ and drinking water were administered directly after surgery, and rat chow was provided ad libitum after $24 \mathrm{~h}$.

Sample collection and analyses of bacterial flora. After 6 weeks, rats were anaesthetized and tissue samples $(1 \mathrm{~cm}$ in diameter) were resected from the jejunum ( $2 \mathrm{~cm}$ from the oesophageojejunostomal anastomosis). Samples were immediately placed on blood agar, MacConkey agar, Brucella blood agar, Bacteroides bile esculine agar and kanamycin/vancomycine agar (Becton Dickinson, Alphen a/d Rijn, the Netherlands). Thereafter, animals were sacrificed by decapitation. The plates were transferred to a $37^{\circ} \mathrm{C}$ incubator and cultured under aerobic ( 24 and $48 \mathrm{~h}$ ) and anaerobic (48 and $120 \mathrm{~h}$ ) conditions. After incubation, pure cultures were isolated from the cultured bacteria, and these were morphologically analysed using the Vitek system (bioMérieux, Boxtel, the Netherlands) [19].

\section{Prospective cohort study}

Patients. Eighty-four consecutive cirrhotic patients from the outpatient clinics of two academic hospitals in the Netherlands were followed prospectively for complications in the period from June 2007 to June 2010. This prospective cohort is primarily aimed to explore relationship between nutritional status and complication rate [20]. Diagnosis of cirrhosis was established by a combination of clinical, laboratory, radiological (ultrasound, MR, CT, Fibroscan ${ }^{\circledR}$, Echosens, Paris, France) and histological findings. Determination of the aetiology of cirrhosis was made using standard diagnostic criteria. For diagnosis of autoimmune hepatitis, the revised autoimmune hepatitis scoring system was used [21]. Alcoholic liver disease was diagnosed in those with regular consumption of at least $60 \mathrm{~g} / 7 \cdot 5$ units (men) or $40 \mathrm{~g} / 5$ units (women) of alcohol daily. Diagnosis of nonalcoholic steatohepatitis was based on clinical data (obesity, metabolic syndrome), liver histopathology and absence of alcohol abuse. Cryptogenic cirrhosis was diagnosed when other causes of cirrhosis had been excluded with appropriate tests. Patients with hepatocellular carcinoma and pegylated interferon-based therapy were excluded as these conditions could interfere with infection risk $(n=15)$. Although acquired immunodeficiency syndrome and other serious diseases were additional exclusion criteria, no patients were excluded for these reasons.

Study design. Patients visited the outpatient clinic at 6-month intervals, or more frequently if indicated. The occurrence of SBP and other bacterial infections, including pneumonia and infection of skin or urinary tract, was registered prospectively. SBP was defined as granulocyte count $>0.25 \times 10^{9} / \mathrm{L}$ in ascites with or without positive ascitic fluid bacterial culture [22,23]. Follow-up ended in case of death, liver transplantation or time of final evaluation (June 1 2010). For the current analysis, charts of all patients were reviewed to investigate whether patients were on acid-suppressive therapy during any period of followup. Start and end date, dosage, treatment duration and indication for use of acid-suppressive therapy were recorded for all patients. Gastro-oesophageal reflux disease (GERD), peptic ulcer disease and gastroprotection in case of nonsteroidal anti-inflammatory drugs (NSAIDs) use were considered valid indications. 


\section{Intestinal permeability}

Patients. Intestinal permeability was evaluated in 12 cirrhotic patients and nine healthy individuals. Subjects with gastrointestinal complaints, renal insufficiency and any co-morbidity other than liver cirrhosis were excluded, and subjects were not allowed to use lactulose, NSAIDs, aspirin or alcohol during 2 weeks prior to the test.

Study design. After an overnight fast, a solution containing 5 g polyethylene glycol (PEG) 400, 5 g PEG 1500 (Bufa Chemical Company, Uitgeest, the Netherlands) and 40 g PEG 3350 (Sigma Chemical Company, St. Louis, MO, USA) dissolved in $100 \mathrm{~mL}$ water was orally administered [24-27]. After ingestion, subjects fasted during another $6 \mathrm{~h}$ and collected urine during a 24-h period in two containers (container I: first $8 \mathrm{~h}$, container II: hours 9-24). Urine samples were stored at $-20{ }^{\circ} \mathrm{C}$ until further analysis by reversed-phase high-performance liquid chromatography as described before [28,29].

These studies were approved by the Medical Ethical Committee for humans as well as the Animal Experiments Committee under the National Experiments on Animals Act and adhered to the rules laid down in the national law that serves the implementation of 'Guidelines on the protection of experimental animals' by the Council of Europe (1986), Directive 86/609/EC. From human subjects, written informed consent was obtained.

\section{Statistical analysis}

SPSS for Windows, version 15.0.1 (SPSS Inc., Chicago, IL, USA), was used for statistical analysis. Values are expressed as means \pm SD for data with Gaussian distribution; otherwise medians with range are used. Proportions were compared using the Pearson chi-square test or Fisher's exact test, where appropriate. Continuous variables were compared using the Student's $t$-test or Mann-Whitney $U$ test, where appropriate. Kaplan-Meier survival analysis with log-rank test was used to compare bacterial infection rates between patients with and without PPI. Cases without bacterial infection were censored at time of liver transplantation, death or end of follow-up.

Multivariate Cox regression analysis was used to identify independent predictors for development of bacterial infection.

A two-sided $P$-value $<0 \cdot 05$ was considered statistically significant.

\section{Results}

\section{Rat study}

All rats in group A (PPI) and C (nontreated) completed the study. Two of 12 rats $(17 \%$ ) treated with GEJ (group B) died before the endpoint of the study because of anastomotic dehiscence (day 4) or stricture at the GEJ anastomosis (day 28). These animals are not included in the analysis. Anaerobic bacterial overgrowth could not be assessed in one PPI-treated rat because of complete overgrowth of the plates by a highly motile swarming Proteus mirablis strain.

Bacterial characterization of bacterial flora. Presence of anaerobic bacteria was more common in jejunum of PPI-treated and GEJ-treated rats compared with controls (Table 1). Clostridium perfringens was demonstrated in the jejunum of all GEJtreated rats and 4/9 PPI-treated rats $(44 \%)$ and none of the nontreated rats. Bacteroides species were found in 4 GEJ-treated rats $(40 \%), 4$ PPI-treated rats $(44 \%)$ and none of the nontreated rats. A variety of other facultative aerobic bacteria species was also present in the jejunum of PPI-treated and GEJtreated rats (Table 1 ).

\section{Prospective cohort study}

Baseline characteristics of the 84 cirrhotic outpatients are given in Table 2.

Use of acid-suppressive drugs. Fifty-two patients (62\%) used an acid-suppressive agent during the study period (pantoprazole or omeprazole in 51 patients, ranitidine in one patient). The vast majority of patients who used acid-suppressive drugs was on a once-daily dosing regimen (42 patients, $82 \%$ ) and used a daily dose of $40 \mathrm{mg}$ ( 44 patients, $86 \%$ ). None of the patients used their drugs on an 'as needed basis'. Median duration of acid-suppressive therapy was 30 months (IQR 11-51 months). In 43 patients $(83 \%)$, no indication for PPI use was documented. In patients with a documented indication, GERD was the most

Table 1 Bacteria found in the jejunum of rats treated with a proton pump inhibitor (PPI), gastrectomy plus oesophagojejunostomy (GEJ) or not treated (controls)

\begin{tabular}{|c|c|c|c|c|}
\hline Bacterial species & $\begin{array}{l}\text { Group A } \\
\text { PPI, \% }\end{array}$ & $\begin{array}{l}\text { Group B } \\
\text { GEJ, \% }\end{array}$ & $\begin{array}{l}\text { Group C } \\
\text { Controls, \% }\end{array}$ & $P$-value \\
\hline $\begin{array}{l}\text { Clostridium } \\
\text { perfringens }\end{array}$ & 44 & 100 & 0 & $<0.01$ \\
\hline Bacteroides spp. & 44 & 40 & 0 & 0.05 \\
\hline Escherichia coli & 100 & 50 & 0 & $<0.01$ \\
\hline Staphyloccus aureus & 33 & 40 & 0 & 0.08 \\
\hline Morganella morganii & 11 & 40 & 0 & 0.05 \\
\hline Streptococcus spp. & 78 & 30 & 10 & 0.01 \\
\hline Lactobacillus spp. & 11 & 0 & 30 & $0 \cdot 14$ \\
\hline $\begin{array}{l}\text { Enterococcus } \\
\text { faecalis }\end{array}$ & 78 & 40 & 0 & $<0.01$ \\
\hline Proteus mirabilis & 33 & 10 & 0 & $0 \cdot 10$ \\
\hline
\end{tabular}


Table 2 Baseline characteristics of 84 cirrhotic patients in prospective cohort study

\begin{tabular}{|c|c|}
\hline \multicolumn{2}{|l|}{ Characteristic } \\
\hline Age (years) & $55 \pm 12$ \\
\hline Male gender $(n)$ & $56(67 \%)$ \\
\hline Body weight (kg) & $78 \pm 19$ \\
\hline \multicolumn{2}{|l|}{ Aetiology cirrhosis $(n)$} \\
\hline Viral hepatitis & $26(31 \%)$ \\
\hline Alcohol & $21(25 \%)$ \\
\hline $\mathrm{PSC} / \mathrm{PBC}$ & $15(18 \%)$ \\
\hline Autoimmune hepatitis & $9(11 \%)$ \\
\hline Other & $13(15 \%)$ \\
\hline \multicolumn{2}{|l|}{ Child-Pugh class $(n)$} \\
\hline$A$ & $49(58 \%)$ \\
\hline B & $29(35 \%)$ \\
\hline $\mathrm{C}$ & $6(7 \%)$ \\
\hline Ascites $(n)$ & $29(35 \%)$ \\
\hline MELD score & $10(6-27)$ \\
\hline On waiting list transplantation $(n)$ & $20(24 \%)$ \\
\hline Diabetes mellitus $(n)$ & $18(21 \%)$ \\
\hline Creatinine $(\mu \mathrm{M})$ & $81(43-247)$ \\
\hline Bilirubin $(\mu \mathrm{M})$ & $24(3-845)$ \\
\hline Prothrombin time (s) & $15 \cdot 1(12 \cdot 4-25 \cdot 5)$ \\
\hline Platelets $\left(\times 10^{9} / \mathrm{L}\right)$ & $116(9-477)$ \\
\hline Serum albumin $(g / L)$ & $35 \cdot 4 \pm 6 \cdot 5$ \\
\hline
\end{tabular}

Data represent mean \pm SD or median (range). MELD, model for end-stage liver disease.

common diagnosis $(n=5,10 \%)$, followed by peptic ulcer disease $(n=2,4 \%)$, gastric protection in case of NSAID use $(n=1$, $2 \%$ ) or a combination of these indications $(n=1,2 \%)$.

Bacterial infections during follow-up. After a median followup of 28 months (IQR 15-31 months), 16 patients died (19\%), because of end-stage liver disease $(n=10)$, hepatocellular carcinoma $(n=2)$ or an unknown cause $(n=4)$. Seventeen patients $(20 \%)$ underwent liver transplantation, whereas the remaining 51 patients $(61 \%)$ survived without liver transplantation or were on the waiting list for transplantation at end of follow-up. A total of 102 hospitalizations occurred in the total cohort of 84 patients, with 33 patients (39\%) without admission, 27 patients $(32 \%)$ being admitted once during follow-up and 24 patients (29\%) with $\geq 2$ admissions. The number of patients admitted at least once during follow-up was significantly higher in PPI users compared with patients who did not use a PPI: 75\% vs. $38 \%(P=0 \cdot 001)$.

A total of 24 patients (29\%) experienced a bacterial infection, requiring treatment with antibiotics. Infection was community acquired in 19 patients $(79 \%)$ and hospital acquired in 5 patients $(21 \%)$. Median duration of follow-up at the time of infection was 6 months (IQR 2-21 months). SBP was diagnosed in nine patients $(11 \%)$, pneumonia and urinary tract infection both in three patients $(4 \%)$, erysipelas and bacterial gastrointestinal infection both in two patients $(2 \%)$, meningitis in one patient $(1 \%)$, diabetic foot infection in one patient $(1 \%)$ and sepsis of unknown origin in three patients $(4 \%)$. Seven patients $(29 \%)$ with a bacterial infection died within 1 month after diagnosis (SBP, $n=4$; urinary tract infection, $n=2$; sepsis of unknown origin, $n=1$ ). Compared with the patients who did not develop a bacterial infection during follow-up, patients with a bacterial infection were older (mean age 60 years vs. 53 years, $P=0.01$ ) and had more advanced liver disease, as expressed by a higher Child-Pugh class (62\% vs. 33\% ChildPugh $\mathrm{B} / \mathrm{C}, P=0.02$ ), lower serum albumin concentration (mean $33.2 \mathrm{~g} / \mathrm{L}$ vs. $36.3 \mathrm{~g} / \mathrm{L}, P=0.05)$ and prolonged prothrombin time (median $16.7 \mathrm{~s}$ vs. $14.5 \mathrm{~s}, P<0.001$ ) (Table 3 ). Of note, follow-up time was significantly shorter in patients with a bacterial infection (median 16 vs. 29 months, $P=0 \cdot 01$ ) (Table 3 ).

Seventeen patients $(71 \%$ ) who developed a bacterial infection during follow-up used a PPI at the time of infection, compared with 34 patients $(57 \%)$ in the noninfection group $(P=0 \cdot 23)$. There were no differences in doses of acid-suppressive drugs between patients with infection and those without infection. Median duration of PPI use at the time of infection was 16 months (IQR 2-44 months). In univariate survival analysis, patients who used a PPI tended to develop an infection more frequently than patients without a PPI (Fig. 1, log-rank test, $P=0 \cdot 11$ ). In multivariate Cox regression analysis, PPI use was not an independent predictor of bacterial infection (HR 1.2, 95\% CI 0.5-3.0, $P=0 \cdot 72$ ) after correction for Child-Pugh class (HR 3.6, 95\% CI 1.5-8.7, P = 0.004) and age (HR 1.05, 95\% CI $1 \cdot 01-1 \cdot 09, P=0 \cdot 02)$. We also conducted the analysis with only SBP as outcome and obtained similar results: in multivariate analysis, Child-Pugh class B/C was an independent predictor of SBP (HR 6.1, 95\% CI 1·2-30.7, $P=0 \cdot 03$ ), whereas PPI use was not (HR 1·8, 95\% CI 0.4-9.1, $P=0 \cdot 46$ ).

Seventeen patients ( $20 \%$ ) died during follow-up, of whom $82 \%$ used a PPI compared with $57 \%$ in patients still alive at the end of follow-up. In univariate survival analysis, mortality was higher among patients who used a PPI compared with those who did not use a PPI (log-rank test $P=0 \cdot 01)$. However, PPI use was not significantly associated with mortality (HR 3.2, 95\% CI 0.9-11.9, $P=0.09$ ) after correction for Child-Pugh class B/C (HR 7.5, 95\% CI 2·3-24.5, $P=0 \cdot 001)$. 
Table 3 Characteristics of cirrhotic patients who did vs. did not develop bacterial infection

\begin{tabular}{|c|c|c|c|}
\hline Characteristic & $\begin{array}{l}\text { Infection } \\
n=24\end{array}$ & $\begin{array}{l}\text { No infection } \\
n=60\end{array}$ & $P$-value \\
\hline Age (years) & $60 \pm 11$ & $53 \pm 12$ & 0.01 \\
\hline Male gender $(n)$ & $17(71 \%)$ & $39(65 \%)$ & 0.61 \\
\hline Body weight (kg) & $76 \pm 26$ & $79 \pm 15$ & 0.62 \\
\hline \multicolumn{4}{|l|}{ Child-Pugh class $(n)$} \\
\hline A & $9(38 \%)$ & $40(67 \%)$ & 0.02 \\
\hline B & $11(46 \%)$ & $18(30 \%)$ & \\
\hline $\mathrm{C}$ & $4(16 \%)$ & $2(3 \%)$ & \\
\hline $\begin{array}{l}\text { On waiting list } \\
\text { transplantation }(n)\end{array}$ & $7(29 \%)$ & $13(22 \%)$ & $0 \cdot 47$ \\
\hline MELD score & $13(6-27)$ & $10(6-16)$ & $<0.01$ \\
\hline Diabetes mellitus $(n)$ & $8(33 \%)$ & $10(17 \%)$ & 0.09 \\
\hline PPI use $(n)$ & $17(71 \%)$ & $34(57 \%)$ & 0.23 \\
\hline $\begin{array}{l}\text { Follow-up duration } \\
\text { (months) }\end{array}$ & $16(0.5-31)$ & $29(0.5-36)$ & 0.01 \\
\hline Prophylaxis SBP $(n)^{\dagger}$ & $2(8 \%)$ & $7(12 \%)$ & 0.66 \\
\hline Creatinine $(\mu \mathrm{M})$ & $93(43-247)$ & $81(53-172)$ & 0.35 \\
\hline Previous SBP $(n)$ & $4(17 \%)$ & $4(7 \%)$ & 0.22 \\
\hline
\end{tabular}

Data represent mean \pm SD or median (range). MELD, model for end-stage liver disease.

SBP, spontaneous bacterial peritonitis.

${ }^{\dagger}$ Norfloxacin $400 \mathrm{mg}$ once daily.

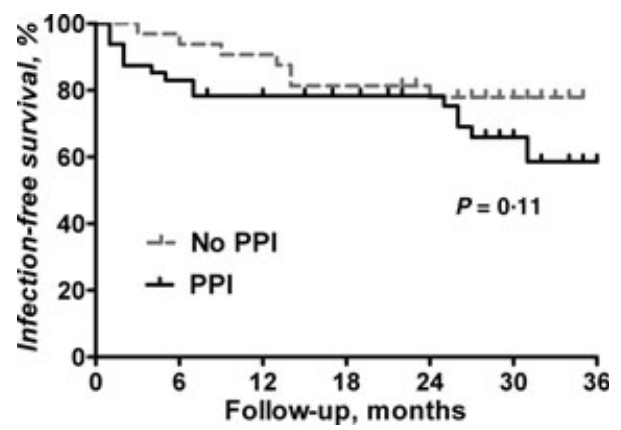

Figure 1 Kaplan-Meier curve comparing bacterial infection rate in 84 cirrhotic patients with vs. without use of PPI (log-rank test $P=0.11$ ). Vertical lines represent bacterial infection, and patients without infection are censored at the time of liver transplantation, death or end of follow-up.

\section{Intestinal permeability}

Polyethylene glycol solution was administered to 12 cirrhotic patients and nine healthy subjects. All subjects had normal renal function. In cirrhotic patients, the underlying cause of cirrhosis was viral hepatitis in $42 \%$, alcohol in 33\% and other in $25 \%$ of patients. Nine patients had Child-Pugh A liver disease $(75 \%)$ and three patients had Child-Pugh B liver disease (25\%). Of the 12 cirrhotic patients, 5 patients (42\%) used a PPI compared with none of the control patients.

Figure 2 shows the recoveries of the various PEGs in cirrhotic patients and healthy controls. PEGs 400, 1500 and 3350 were largely excreted within the first $8 \mathrm{~h}$ after the administration of PEG solution (Fig. 2b,d,f), with the exception of PEG 3350 in cirrhotic patients (Fig. 2f). No significant differences in 24-h recoveries of PEG 400 were observed between cirrhotic patients [median 31\% (IQR 28-39)] and healthy controls [29\% (25-30), $P=0 \cdot 16$ ] (Fig. 2a). In contrast, 24-h recoveries of PEG 1500 [2.1\% (1.5-4.2) vs. $1 \cdot 3 \%(0 \cdot 9-1 \cdot 7), P=0 \cdot 02$, Fig. 2 c] and PEG $3350(0 \cdot 19 \%(0 \cdot 13-0 \cdot 28)$ vs. $0 \cdot 11 \%(0 \cdot 09-0 \cdot 18), P=0 \cdot 02$, Fig. 2 e) were significantly higher in cirrhotic patients compared with healthy controls. No significant differences in intestinal permeability between cirrhotic PPI users and cirrhotic patients who did not use a PPI were found (data not shown).

\section{Discussion}

In this study, we explored a possible association between PPI use and occurrence of bacterial infections in cirrhotic outpatients as well as potential contributing mechanisms. Our experimental animal data indicated bacterial overgrowth in rats treated with PPI, comparable to rats that underwent GEJ. Bacterial infection rate in our cohort of consecutive cirrhotic outpatients was high, but was not found to be related to PPI use. In contrast, state of liver disease was the most important factor in the development of bacterial infections, with Child-Pugh B or C patients having a threefold increased risk of bacterial infection compared with Child-Pugh A patients. Furthermore, increasing age was an independent predictor of bacterial infections. We also conducted the analysis with only SBP as outcome and obtained similar results.

Previous reports on PPI use and infection risk in cirrhotic patients focused on SBP only and - except for one study - only included hospitalized patients with ascites [6,15-18]. In a retrospective matched case-control study among 140 cirrhotic inpatients with ascites, prehospital PPI use and low ascitic fluid protein content were independent predictors of SBP [15]. In line with these results, in a recent retrospective review of 176 cirrhotic inpatients, PPI use was found to be an independent risk factor for the development of SBP besides Child-Pugh class $\mathrm{C}$ and high model for end-stage liver disease (MELD) scores [17]. In contrast, a retrospective cohort study in 116 consecutive cirrhotic patients with ascites who underwent diagnostic paracentesis upon hospital admission did not find an association between PPI use and development of SBP [16]. Furthermore, in 

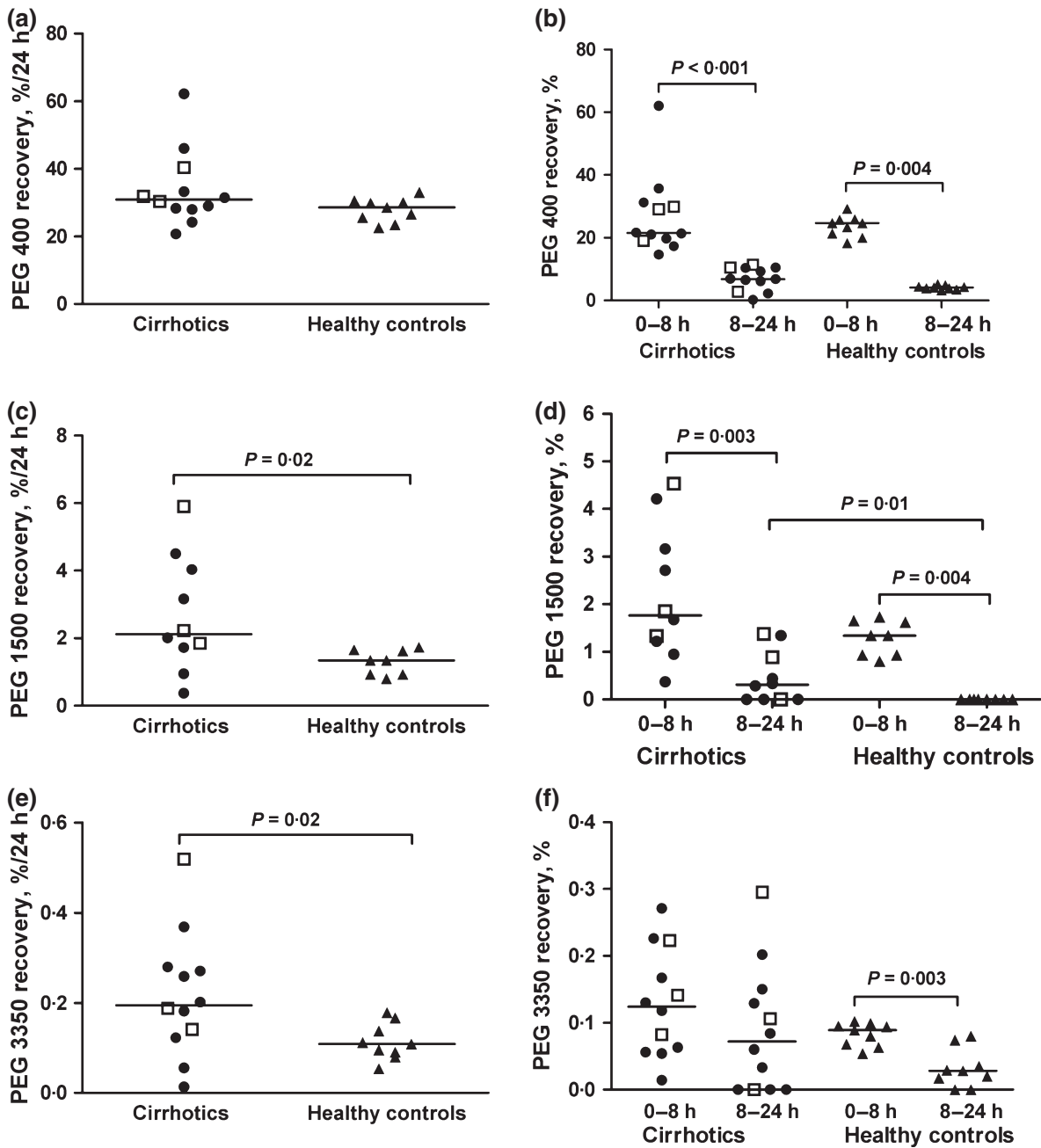

Figure 2 Cumulative 0- to 24-h recoveries of polyethylene glycols with molecular mass 400 (a), 1500 (c) and 3350 (e) as well as relative 0 - to 8 -h and 8- to 24 -h recoveries of the same molecules (b, $d$ and $f$ ) in cirrhotics patients compared with healthy controls. Each symbol represents one subject, with circles indicating Child-Pugh A cirrhotics, squares Child-Pugh B cirrhotics and triangles healthy controls. The horizontal line indicates the median value for cirrhotics and healthy controls. Only $P$-values $<0.05$ are shown.

the only other available study in cirrhotic outpatients, no significant association between use of acid-suppressive therapy and occurrence of SBP was found [6]. Differences between various studies may relate to different patient characteristics. For example, a priori chance of infection or SBP is much higher in admitted patients with persistent ascites compared with outpatients. Furthermore, frequency of PPI use varied greatly between these studies [6,15-17].

Of importance, in our study, PPIs were often prescribed in cirrhotic patients without an accepted indication. Although PPIs are generally regarded to be drugs with a good safety profile, previous reports in noncirrhotic patients indicate that PPI use is associated with an increased risk of community-acquired pneumonia [14], as well as Clostridium difficile infection and other enteric infections [30]. Therefore, routine use of acid-suppressive drugs in cirrhotic patients is not recommended in the absence of an appropriate indication. Clinicians should constantly re-evaluate the use of PPIs in both cirrhotic inpatient and outpatients.

An alternative explanation for the high infection rate in cirrhotic patients could be increased intestinal permeability. In line with this hypothesis, we found intestinal permeability to be increased in cirrhotic patients compared with healthy controls, in line with earlier reports $[9,10]$. We used PEGs of different molecular masses which allow assessment of size-dependent intestinal permeability [24,25]. In contrast to 
previously used permeability tests as ${ }^{51} \mathrm{Cr}$-EDTA and sugar absorption tests, the PEG solution contains relatively large compounds (PEG 3350) that mimic the structure of bacterial endotoxins as lipopolysaccharide [24,25]. One might speculate that PPI use among cirrhotic patients might have influenced our results. However, we did not find a significant difference in intestinal permeability between cirrhotic patients with and without PPI.

Aetiology of bacterial infections in cirrhotic patients is probably multifactorial. It is known that intestinal permeability, gut flora and motility are altered in cirrhotic patients [31-34]. Furthermore, several abnormalities in immune response have been described in cirrhotic patients [11,12]. As these risk factors already exist in cirrhotic patients not on PPI therapy, use of PPIs might not have a significant additional effect on infection risk.

In conclusion, although in our animal model PPIs induced intestinal overgrowth, stage of liver disease rather than PPI use was the predominant factor determining infection risk in cirrhotic patients. Increased intestinal permeability may be a factor contributing to infection risk.

\section{Acknowledgements}

We thank Martin de Smet for the PEG measurements.

\section{Source of funding}

None.

\section{Conflict of interests}

The authors who have taken part in this study declared that they do not have anything to disclose regarding funding or conflict of interest with respect to this manuscript.

\section{Authors contribution}

LGvV, EJH: data collection, data analysis, writing of manuscript, BvH, WR: data collection, critical revision of manuscript, FWMdR: design of study, data collection, critical revision of manuscript, PDS: design of study, critical revision of manuscript, KJvE: design of study, writing of manuscript.

\section{Address}

Department of Gastroenterology and Hepatology, University Medical Center Utrecht, Utrecht (L. G. van Vlerkenm, E. J. Huisman, P. D. Siersema, K. J. van Erpecum); Department of Gastroenterology and Hepatology, Leiden University Medical Center, Leiden (B. van Hoek); Department of Surgery, University Medical Center Utrecht, Utrecht (W. Renooij); Department of Internal Medicine, Erasmus Medical Center, Rotterdam, The Netherlands (F. W. M. de Rooij).

Correspondence to: Dr K. J. van Erpecum, Department of Gastroenterology and Hepatology F·02·618, University Medical Center Utrecht, PO Box 85500, 3508 GA Utrecht, The Nether- lands. Tel.: +31 88 7555555; fax: +31 88 7555533;

e-mail:k.j.vanerpecum@umcutrecht.nl

Received 23 August 2011; accepted 28 December 2011

\section{References}

1 Christou L, Pappas G, Falagas ME. Bacterial infection-related morbidity and mortality in cirrhosis. Am J Gastroenterol 2007;102:1510-7.

2 Borzio M, Salerno F, Piantoni L, Cazzaniga M, Angeli P, Bissoli F et al. Bacterial infection in patients with advanced cirrhosis: a multicentre prospective study. Dig Liver Dis 2001;33:41-8.

3 Fernandez J, Navasa M, Gomez J, Colmenero J, Vila J, Arroyo V et al. Bacterial infections in cirrhosis: epidemiological changes with invasive procedures and norfloxacin prophylaxis. Hepatology 2002;35:140-8.

4 Merli M, Lucidi C, Giannelli V, Giusto M, Riggio O, Falcone M et al. Cirrhotic patients are at risk for health care-associated bacterial infections. Clin Gastroenterol Hepatol 2010;8:979-85.

5 Arvaniti V, D'Amico G, Fede G, Manousou P, Tsochatzis E, Pleguezuelo $\mathrm{M}$ et al. Infections in patients with cirrhosis increase mortality four-fold and should be used in determining prognosis. Gastroenterology 2010;139:1246-56.

6 Bauer TM, Steinbruckner B, Brinkmann FE, Ditzen AK, Schwacha $\mathrm{H}$, Aponte JJ et al. Small intestinal bacterial overgrowth in patients with cirrhosis: prevalence and relation with spontaneous bacterial peritonitis. Am J Gastroenterol 2001;96:2962-7.

7 Wiest R, Garcia-Tsao G. Bacterial translocation (BT) in cirrhosis. Hepatology 2005;41:422-33.

8 Ersoz G, Aydin A, Erdem S, Yuksel D, Akarca U, Kumanlioglu K. Intestinal permeability in liver cirrhosis. Eur J Gastroenterol Hepatol 1999;11:409-12.

9 Scarpellini E, Valenza V, Gabrielli M, Lauritano EC, Perotti G, Merra $\mathrm{G}$ et al. Intestinal permeability in cirrhotic patients with and without spontaneous bacterial peritonitis: is the ring closed? Am J Gastroenterol 2010;105:323-7.

10 Cariello R, Federico A, Sapone A, Tuccillo C, Scialdone VR, Tiso A et al. Intestinal permeability in patients with chronic liver diseases: its relationship with the aetiology and the entity of liver damage. Dig Liver Dis 2010;42:200-4.

11 Fiuza C, Salcedo M, Clemente G, Tellado JM. In vivo neutrophil dysfunction in cirrhotic patients with advanced liver disease. J Infect Dis 2000;182:526-33.

12 Rimola A, Soto R, Bory F, Arroyo V, Piera C, Rodes J. Reticuloendothelial system phagocytic activity in cirrhosis and its relation to bacterial infections and prognosis. Hepatology 1984;4:53-8.

13 Driks MR, Craven DE, Celli BR, Manning M, Burke RA, Garvin GM et al. Nosocomial pneumonia in intubated patients given sucralfate as compared with antacids or histamine type 2 blockers. The role of gastric colonization. $N$ Engl J Med 1987;317:1376-82.

14 Johnstone J, Nerenberg K, Loeb M. Meta-analysis: proton pump inhibitor use and the risk of community-acquired pneumonia. Aliment Pharmacol Ther 2010;31:1165-77.

15 Bajaj JS, Zadvornova Y, Heuman DM, Hafeezullah M, Hoffmann RG, Sanyal AJ et al. Association of proton pump inhibitor therapy with spontaneous bacterial peritonitis in cirrhotic patients with ascites. Am J Gastroenterol 2009;104:1130-4.

16 Campbell MS, Obstein K, Reddy KR, Yang YX. Association between proton pump inhibitor use and spontaneous bacterial peritonitis. Dig Dis Sci 2008;53:394-8. 
17 Choi EJ, Lee HJ, Kim KO, Lee SH, Eun JR, Jang BI et al. Association between acid suppressive therapy and spontaneous bacterial peritonitis in cirrhotic patients with ascites. Scand J Gastroenterol 2011;46:616-20.

18 Trikudanathan G, Israel J, Cappa J, O'Sullivan DM. Association between proton pump inhibitors and spontaneous bacterial peritonitis in cirrhotic patients - a systematic review and meta-analysis. Int J Clin Pract 2011;65:674-8.

19 Reisner BS, Woods GL, Thomson RB Jr, Larone DH, Garcia LS, Shimizu RY. General issues in clinical microbiology: general processing. In: Murray PR, Baron EJ, Pfaller MA, Tenover FC, Yolken RH, editors. Manual of Clinical Microbiology, 7th edn. Washington, DC, USA: ASM Press; 1999: pp 64-104.

20 Huisman EJ, Trip E, van Hoek B, Siersema PD, van Erpecum KJ. Protein energy malnutrition predicts complications in liver cirrhosis. Eur J Gastroenterol Hepatol 2011;23:982-9.

21 Alvarez F, Berg PA, Bianchi FB, Bianchi L, Burroughs AK, Cancado EL et al. International Autoimmune Hepatitis Group Report: review of criteria for diagnosis of autoimmune hepatitis. J Hepatol 1999;31:929-38.

22 Rimola A, Garcia-Tsao G, Navasa M, Piddock LJ, Planas R, Bernard $\mathrm{B}$ et al. Diagnosis, treatment and prophylaxis of spontaneous bacterial peritonitis: a consensus document. International Ascites Club. J Hepatol 2000;32:142-53.

23 Runyon BA. Management of adult patients with ascites due to cirrhosis. Hepatology 2004;39:841-56.

24 Parlesak A, Bode JC, Bode C. Parallel determination of gut permeability in man with M(r) 400, M(r) 1500, M(r) 4000 and M(r) 10,000 polyethylene glycol. Eur J Clin Chem Clin Biochem 1994;32:813-20.

25 Parlesak A, Schafer C, Schutz T, Bode JC, Bode C. Increased intestinal permeability to macromolecules and endotoxemia in patients with chronic alcohol abuse in different stages of alcohol-induced liver disease. J Hepatol 2000;32:742-7.

26 Ammori BJ, Fitzgerald P, Hawkey P, McMahon MJ. The early increase in intestinal permeability and systemic endotoxin exposure in patients with severe acute pancreatitis is not associated with systemic bacterial translocation: molecular investigation of microbial DNA in the blood. Pancreas 2003;26:18-22.

27 Ammori BJ, Leeder PC, King RF, Barclay GR, Martin IG, Larvin M et al. Early increase in intestinal permeability in patients with severe acute pancreatitis: correlation with endotoxemia, organ failure, and mortality. J Gastrointest Surg 1999;3:252-62.

28 Kerckhoffs AP, Akkermans LM, de Smet MB, Besselink MG, Hietbrink F, Bartelink IH et al. Intestinal permeability in irritable bowel syndrome patients: effects of NSAIDs. Dig Dis Sci 2010;55:716-23.

29 Besselink MG, van Santvoort HC, Renooij W, de Smet MB, Boermeester MA, Fischer $\mathrm{K}$ et al. Intestinal barrier dysfunction in a randomized trial of a specific probiotic composition in acute pancreatitis. Ann Surg 2009;250:712-9.

30 Dial MS. Proton pump inhibitor use and enteric infections. Am J Gastroenterol 2009;104(Suppl 2):S10-6.

31 Chang CS, Chen GH, Lien HC, Yeh HZ. Small intestine dysmotility and bacterial overgrowth in cirrhotic patients with spontaneous bacterial peritonitis. Hepatology 1998;28:1187-90.

32 Chesta J, Defilippi C, Defilippi C. Abnormalities in proximal small bowel motility in patients with cirrhosis. Hepatology 1993;17:828-32.

33 Pande C, Kumar A, Sarin SK. Small-intestinal bacterial overgrowth in cirrhosis is related to the severity of liver disease. Aliment Pharmacol Ther 2009;29:1273-81.

34 Pardo A, Bartoli R, Lorenzo-Zuniga V, Planas R, Vinado B, Riba J et al. Effect of cisapride on intestinal bacterial overgrowth and bacterial translocation in cirrhosis. Hepatology 2000;31:858-63. 